\title{
The impact of vascular calcification among dialysis dependent south African CKD patients: A five year follow up study. \\ Cardiovascular mortality and morbidity, ethnic variation and hemodynamic correlates
}

Kudakwashe SIMBA ( $\nabla$ kudadoc@gmail.com )

University of Cape Town Chancellor Oppenheimer Library https://orcid.org/0000-0003-1829-154X

Megan BORKUM

University of Cape Town Department of Medicine

Nalene STRAUSS

University of Cape Town Department of Medicine

Wisdom BASERA

University of Cape Town School of Public Health and Family Medicine

Charles SWANEPOEL

University of Cape Town Department of Medicine

Robert Jeremy FREERCKS

University of Cape Town Department of Medicine

Brian Lindsay RAYNER

University of Cape Town Department of Medicine

Research article

Keywords: ,

Posted Date: August 30th, 2019

DOI: https://doi.org/10.21203/rs.2.13757/v1

License: (9) This work is licensed under a Creative Commons Attribution 4.0 International License.

Read Full License 


\section{Abstract}

BACKGROUND Vascular calcification is a risk factor for cardiovascular morbidity and mortality in patients with end stage renal disease (ESRD). In Western countries, Blacks with ESRD appear to have lesser degrees of vascular calcification compared to non-Blacks. However, there is no published data on the association of ethnic differences in vascular calcification and survival in ESRD from Sub-Saharan Africa.

METHODS This study assessed 5-year changes in vascular calcification and mortality in a previously published cohort of patients with ESRD. Vascular calcification was assessed by abdominal aortic calcification score and vascular stiffness by pulse wave velocity.

RESULTS Sixty-six of the original 74 participants, studied at baseline, were identified. The median age was 46.6 years (37.6-59.2) and $57.6 \%$ were women. Abdominal aortic calcification showed no progression among Blacks [baseline range $0-5$, follow up range $0-8(p=1.00)$ ], but a non-significant trend to progression among non-Blacks [baseline range $0-19$, follow up range $0-22(p=0.066)$ ]. Black participants did not display a survival advantage $(p=0.870)$. Overall, sepsis was the most common cause of mortality ( $64 \%$ of those with an identifiable cause of death). Non-Blacks had higher parathyroidectomy rates than Blacks with $9 / 30$ cases compared to $2 / 36(p=0.036)$. After adjustment for parathyroidectomy at follow up, the odds ratio of having abdominal vascular calcification score of $\geq 1$ amongst non-Blacks was 8.6-fold greater compared to Blacks $(p=0.03)$. Central aortic systolic pressures (CASP) and pulse wave velocities (PWV) were higher in the study population than age matched normative values. At follow up, a positive correlation ( $r=0.5)$ was observed between PWV and abdominal aortic calcification $(p=0.047)$. Elevated baseline coronary artery calcification score and FGF-23 level at baseline were not associated with a difference in mortality.

CONCLUSION There was no significant progression in vascular calcification among Blacks. After adjusting for increased parathyroidectomy rates, there was a greater progression of vascular calcification amongst non-Blacks compared to Blacks highlighting possible ethnic differences in calcium phosphate metabolism in patients with ESRD. Lack of vascular calcification progression in Blacks was not associated with improved survival, but the sample size was small.

\section{Background}

Chronic Kidney Disease (CKD) is a major public health problem in South Africa (SA) due to the high prevalence of hypertension, diabetes and HIV. ${ }^{1,2,3}$ A population based sample study conducted in Bellville, Cape Town using the Modification of Diet in Renal Disease (MDRD) equation to calculate the estimated glomerular filtration rate, demonstrated a high prevalence of CKD stage $3-5$ of $7.6 \%$ (with ethnicity correction) and $23.9 \%$ (without ethnicity correction). ${ }^{4} \mathrm{CKD}$ has a higher cardiovascular(CV) mortality due to traditional risk clustering of CV as well as non-traditional CV risk factors, including vascular calcification of the tunica media. ${ }^{5}$ 
Various surrogate markers have been used to assess vascular health in patients with CKD. ${ }^{6}$ The extent of coronary artery calcification has shown to be a powerful clinical predictor of long term prognosis in asymptomatic CKD patients. ${ }^{7}$ Furthermore, Fibroblast Growth Factor 23 (FGF-23) is positively associated with left ventricular hypertrophy (LVH), endothelial dysfunction, progression of CKD and a higher mortality. ${ }^{8,9}$ Pulse wave velocity (PWV) and central aortic systolic pressure (CASP) can be used non-invasively to measure vascular health. ${ }^{9}$ In CKD, regardless of the stage, patients have higher PWV level compared to controls with preserved renal function. ${ }^{10}$ Blacher et al ${ }^{11}$ showed that, in patients with ESRD, increased PWV was a strong independent predictor of CV and all-cause mortality. Vascular calcification, atherosclerosis, changes in collagen and elastin, and uremia are all thought to result in increased arterial stiffness in CKD. ${ }^{12}$

Ethnicity may also play a role in the development of vascular calcification. Numerous studies in developed countries describes slower progression of vascular calcification in Blacks compared to nonBlacks. ${ }^{13,14}$. Freercks et al ${ }^{15}$ showed that Black South African dialysis patients appeared to be protected from vascular calcification. The median coronary calcium score among Blacks was 0 (IQR 0) and 66 nonBlacks (IQR $383 p<0.01)^{15}$. Even after adjustment, Black race remained a negative predictor for coronary calcification ${ }^{15}$. There is a paucity of other data on ethnic variations in vascular calcification in subSaharan Africa. This apparent advantage for Blacks on dialysis may be due to a lower pro-inflammatory state, dietary intake, genetic factors and variations in bone mineral metabolism. 7,10,16 Differences in ethnic bone mineral metabolism regulation, bone mass acquisition and architecture are well described. ${ }^{16-22}$ Black subjects with end stage renal disease (ESRD) have been shown to have a more favorable bone density and bone architecture, less calcium renal excretion, elevated gastrointestinal calcium absorption, lower 25-hydroxy vitamin D and higher levels of parathyroid hormone (PTH) than their non-Black counterparts. ${ }^{17,18,19}$

The present study is a five year follow up, single centre study of patients initially recruited to investigate vascular calcification in dialysis-dependent patients. ${ }^{15}$ The study aimed to assess the progression of vascular calcification and ensuing clinical sequelae as well as the possible survival advantage of Blacks on dialysis. The study protocol was approved by the Human Research Ethics Committee of the University of Cape Town (HREC REF: 048/2016).

\section{Methods}

Of the 74 patients recruited in the initial study, 66 were traced. All study participants were over 18 years old and provided written informed consent. Testing was conducted on the dialysis patients after completion of dialysis and on pre-scheduled clinic appointment visits in non-dialysis dependent patients. The cohort's study methods have been described in detail elsewhere ${ }^{20}$, but included: baseline anthropometry, electrocardiogram (ECG), abdominal calcification scores (calculated from lateral abdominal radiograph), coronary calcium scores (CCS) calculated from a cardiac computer tomography, and FGF-23 levels. Medical data including smoking habits and dialysis modality were captured. The 
following investigations were done at the 5-year follow-up visit: anthropometry, lateral abdominal radiograph, ECG, and PWV and CASP measurement using the AtCor Medical SphygmoCor XCEL ${ }^{\circledR}$ device.

All anthropometric measurements were conducted by one investigator (KS). The peritoneal dialysis patient was weighed after drainage of the dialysate. All haemodialysis patients had their weights measured post dialysis. Abdominal truncal obesity was defined using the African normative values of waist circumference of male $\geq 94 \mathrm{~cm}$ and females $\geq 80 \mathrm{~cm}^{21}$

All resting ECGs were performed using standard calibration and analyzed by one investigator (SK). The Sokolow-Lyon (SL) and Cornell Criteria, as per European Society Cardiology guidelines, were used to diagnose left ventricular hypertrophy $(\mathrm{LVH})^{22}$ and were corrected for body mass index (BMI). ${ }^{23}$

Abdominal radiographs were taken using a standardized technique. ${ }^{15}$ Scoring of calcification was assessed as per 24-point scale using the validated method described by Kaupilla et al. ${ }^{24}$ The same investigator (RF) who conducted the abdominal calcification scoring in the initial study was blinded and scored all the radiographs done at follow up.

The data were entered into a RedCap database and cleaned using pivot tables in Microsoft Excel before being exported to STATA 14 (Stata Corp, College Station, Texas) for analysis. Statistical tests were performed according to whether the variable was continuous or categorical. Continuous data are expressed as mean values \pm SD or median values (IQR) depending on the normality of data. For categorical data the $\chi^{2}$ test or Fisher exact test and the $Z$ test were used to test for a statistical difference between variables and proportions, respectively. The Mann-Whitney and Student $t$ test were used to test the association between continuous and categorical variables. Participants of African descent were classified as Blacks. The rest were classified as non-Blacks for analysis.

The survival of Blacks versus non-Blacks at 5 years was analyzed using Kaplan Meir curves. The difference in progression of vascular calcification among Blacks and non-Blacks at baseline and followup was analyzed using the paired t-tests and sign-rank paired test based on normality. PWV measurements were not undertaken in the initial study. Using normative values of PWV published in a South African study ${ }^{25}$, the effects of vascular calcification on PWV were identified. A BPro watch device (HealthSTATS, Singapore) was used to measure the CASP in the initial study. The five-year clinical outcome in relation to calcium scores at baseline was analysed using the Student's t-test.

\section{Results}

Baseline and follow-up characteristics of the population are presented in table 1. At baseline and follow up $57.6 \%$ of participants were women $(n=38)$ and $54.5 \%$ were Black $(n=36)$. The majority of patients traced were still alive $63.6 \%(n=42)$. Among participants that were alive: $57.1 \%(n=24)$ had been transplanted, $40.5 \%(n=17)$ were on hemodialysis and one patient was on peritoneal dialysis. NonBlacks had progressive abdominal calcification approaching significance [baseline range $0-5$, follow up 
range $=0-8(p=0.066)$ ] compared to Blacks who showed no progression [baseline range $=0-19$, follow up range $0-22(p=1.00)$ ]. Non-Blacks had higher parathyroidectomy rates of $9 / 30$ cases compared to $2 / 36$ cases of Black patients $(p=0.036)$. The odds ratio of having abdominal vascular calcification score of $\geq 1$ amongst non-Blacks at follow up was 8.6 fold greater than a similar calcification score amongst Blacks, after having adjusted for parathyroidectomy $(p=0.031)$. At follow up, a positive correlation $(r=$ 0.3 ) was observed between PWV and abdominal vascular calcification $(p=0.04)$. Significant weight gain among all participants at follow up compared to baseline was observed $\left(27.1 \pm 7.1 \mathrm{~kg} / \mathrm{m}^{2}\right.$ versus $24.4 \pm 4.2 \mathrm{~kg} / \mathrm{m}^{2}$ respectively; $\left.\mathrm{p}<0.015\right)$. There was a regression in $\mathrm{LVH}$ using both the $\mathrm{SL}$ score corrected for BMI $(p<0.001)$ and Cornell product corrected for BMI $(p=0.027)$. In our study group $12.1 \%(n=4)$ of transplanted patients during follow up developed new onset diabetes after transplantation (NODAT). Infections were the most common cause of morbidity (50.8\%) followed by: ischemic heart disease (38.5\%), gout (10.8\%), NODAT (6.0\%), peripheral vascular disease $(3.1 \%)$, cerebrovascular accidents (3.1\%), peripheral neuropathy (3.1\%), depression (1.5\%) and vertebral fractures (1.5\%).

There was no difference in survival by ethnicity $(p=0.870)$ (Figure 1). The renal replacement modality of participants who had died at follow-up included: $38 \%$ transplant $(n=9), 16 \%$ peritoneal dialysis $(n=4)$, $38 \%$ hemodialysis $(n=9)$ and $8 \%$ had no data $(n=2)$. Overall, sepsis was a major cause of mortality in our study group, seen in 9 of 14 participants (64\%) in whom a cause of death could be identified. More participants with a CCS $\geq 1$ at baseline were on dialysis than had been transplanted at follow up $(p=$ 0.035) (Table 3). Participants with coronary calcification had a higher numerical probability of dying $(43.3 \%$ versus $30.6 \% ; p=0.213)$.

\section{Table 1: Characteristics of the study population at baseline and follow-up}




\begin{tabular}{|c|c|c|c|c|c|}
\hline CHARACTERISTIC & \multicolumn{2}{|c|}{ BASELINE (74) } & \multicolumn{2}{|c|}{ FOLLOW-UP (66) } & P-VALUE \\
\hline AGE, median (IQR) & \multicolumn{2}{|c|}{$42.1(32.7-49.3)$} & \multicolumn{2}{|c|}{$46.6(37.6-59.2)$} & $<0.0001^{\circ}$ \\
\hline WOMEN n, \% & \multicolumn{2}{|c|}{$42(56.8)$} & \multicolumn{2}{|c|}{$38(57.6)$} & $0.922 \dagger$ \\
\hline BLACKS n, \% & \multicolumn{2}{|c|}{$40(54.1)$} & \multicolumn{2}{|c|}{$36(54.5)$} & $0.954+$ \\
\hline \multicolumn{6}{|l|}{ RENAL REPLACEMENT STATUS, n (\%) } \\
\hline $\mathrm{HD}$ & & & \multicolumn{2}{|c|}{$28(42.4)$} & \\
\hline PD & & & \multicolumn{2}{|c|}{$5(7.6)$} & \\
\hline Transplant & & & \multicolumn{2}{|c|}{$33(50.0)$} & \\
\hline \multicolumn{6}{|l|}{ ALIVE, $n(\%)$} \\
\hline All & & & \multicolumn{2}{|c|}{$42(63.6)$} & \\
\hline $\mathrm{HD}$ & & & \multicolumn{2}{|c|}{$17(40.5)$} & \\
\hline PD & & & \multicolumn{2}{|c|}{$1(2.4)$} & \\
\hline Transplant & & & \multicolumn{2}{|c|}{$24(57.1)$} & \\
\hline BMI & \multirow{2}{*}{\multicolumn{2}{|c|}{$24.3( \pm 4.1)$}} & \multirow{2}{*}{\multicolumn{2}{|c|}{$27.1( \pm 7.1)$}} & \\
\hline All & & & & & $0.015 \ddagger$ \\
\hline Transplanted & \multicolumn{2}{|c|}{$24.6( \pm 3.4)$} & \multicolumn{2}{|c|}{$27.4( \pm 8.3)$} & $0.100 \ddagger$ \\
\hline Dialysis & \multicolumn{2}{|c|}{$24.1( \pm 4.7)$} & \multicolumn{2}{|c|}{$26.6( \pm 5.1)$} & $0.008 \ddagger$ \\
\hline \multicolumn{6}{|l|}{ DM INCIDENCE } \\
\hline All & & & \multicolumn{2}{|c|}{$4(6.0)$} & \\
\hline Transplant & & & \multicolumn{2}{|c|}{$4(12.1)$} & \\
\hline Dialysis & & & \multicolumn{2}{|c|}{0} & \\
\hline Blacks & & & \multicolumn{2}{|c|}{$4(11.1)$} & $0.131+$ \\
\hline Non-Blacks & & & \multicolumn{2}{|c|}{0} & \\
\hline ABDO CALC (mean, SD)(mode) & & & & & \\
\hline Blacks & $0.4( \pm 1.3)$ & $0-5$ & $0.6( \pm 1.9)$ & $0-8$ & $1.000 \neq$ \\
\hline Non-Blacks & $4.9( \pm 7.1)$ & $0-19$ & $5.6( \pm 6.9)$ & $0-22$ & $0.066 \neq$ \\
\hline $\begin{array}{c}\text { LVH } \\
\text { SL Score corrected for BMl } \\
\left(\mathrm{mm}^{\star} \mathrm{kg}, \mathrm{m}^{2}\right)\end{array}$ & \multicolumn{2}{|c|}{$939( \pm 376)$} & \multicolumn{2}{|c|}{$671( \pm 280)$} & $<0.001 \ddagger$ \\
\hline SL Score corrected for BMI Blacks & \multirow{2}{*}{\multicolumn{2}{|c|}{$\begin{array}{l}926( \pm 364) \\
954( \pm 407)\end{array}$}} & $\begin{array}{l}696( \pm \\
666(+\end{array}$ & & $\begin{array}{l}0.068 \ddagger \\
0.002 \ddagger\end{array}$ \\
\hline 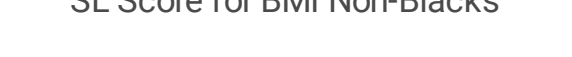 & & & & & $0.002+$ \\
\hline
\end{tabular}

- Mann-Whitney U test

‡ Student's t-test

† Z-test

0255075100Proportion of patients with the outcome of death (\%)3027(3)26(1)24(2)21(3)19(2)ethnicity = non-black3635(1)32(3)30(2)27(3)22(3)ethnicity = blackNumber at risk012345

Analysis time (years) 
BlacksNon-blackslog rank p-value $=0.870$ Kaplan-Meier estimates for patients who died at follow-up according to race 000255075100 Proportion of patients with the outcome of death

(\%)3027(3)26(1)24(2)21(3)19(2)ethnicity = non-black3635(1)32(3)30(2)27(3)22(3)ethnicity = blackNumber at risk012345

Analysis time (years)

BlacksNon-blackslog rank $p$-value $=0.870 \mathrm{Kaplan}$-Meier estimates for patients who died at follow-up according to race Figure 1: Kaplan-Meier estimates of patients who had died at follow-up according to race

All females and $85 \%$ of male participants had truncal obesity at follow up. ${ }^{21}$ The median abdominal circumference of males was $96.5 \mathrm{~cm}$ (IQR: $93-102.5 \mathrm{~cm}$ ), $2.7 \%$ above the African normative values. Females had a median abdominal circumference of 101.5cm (IQR: $90-108 \mathrm{~cm}$ ), 27\% above normative African values. There was no difference in abdominal obesity between Blacks and non-Blacks ( $p=$ 0.254). The median BMI at follow up for participants who developed NODAT was $23.4 \mathrm{~kg} / \mathrm{m}^{2}(19.5-27.2)$ compared to those who did not develop NODAT $27.5 \mathrm{~kg} / \mathrm{m}^{2}(23.7-31.4)(p=0.095)$. A mean weight gain of $1.1 \mathrm{~kg}$ (1.5) was observed among participants who developed NODAT compared to $4.8 \mathrm{~kg}(3.4)(\mathrm{p}=$ 0.072 ) in participants who did not develop NODAT. In our study group, only Black participants developed NODAT (Table 1).

At baseline non-Blacks had a higher numerical median FGF-23 compared to Blacks $(p=0.513)$. Study participants who had higher FGF-23 at baseline had a higher probability of death that approached significance $(p=0.075)$. FGF-23 could not be measured at follow up.

Using normative values among an age-stratified South African population, higher median values of PWV were observed among participants in the age groups below 60 years compared to normative values (Table 2) ${ }^{24}$ A positive correlation between PWV and abdominal calcification was observed at follow up ( $r$ $=0.5, p=0.047$ ) Baseline CASP was not a predictor of outcome at follow up, baseline mean CASP was $134.5 \mathrm{mmHg}( \pm 24.1)$ for participants alive at follow up compared to baseline CASP of $132.1 \mathrm{mmHg}$ $( \pm 29.2)$ in those who had died at follow up $(p=0.723)$.

\section{Table 2: Pulse wave velocity at follow up compared to African normative values}




\begin{tabular}{cclc}
\hline $\begin{array}{c}\text { Pulse wave velocity } \\
\text { Males \& Females }\end{array}$ & $\begin{array}{c}\text { Normative Values }{ }^{24} \\
\text { Value } 50^{\text {th }}\left(10^{\text {th }} 90^{\text {th }}\right)\end{array}$ & \multicolumn{2}{c}{ Value $50^{\text {th }}(\mathrm{n})\left(10^{\text {th }} 90^{\text {th }}\right)$} \\
20-29 years & $6.1(5.3,7.10)$ & $6.6(7)$ & $(5.3,8.6)$ \\
30-39 years & $6.4(5.2,8.00)$ & $7.3(7)$ & $(4.9,13.1)$ \\
40-49 years & $6.9(5.9,8.60)$ & $8.1(14)$ & $(6.3,10.4)$ \\
50-59 years & $8.1(6.3,10.0)$ & $8.8(5)$ & $(6.5,12.3)$ \\
$60-69$ years & $10.3(9.7,13.1)$ & $8.1(1)$ & \\
\hline
\end{tabular}

\section{Table 3: Patient characteristics at follow up, stratified by baseline coronary calcium scores (CCS)}

\begin{tabular}{lccc}
\hline CHARACTERISTIC & CCS $=0$ & CCS $\geq 1$ & P-VALUE \\
\hline Current status, $\mathbf{n}(\%)$ & & & \\
Haemodialysis & $12 / 36(33.3)$ & $15 / 27(55.6)$ & $0.015 \AA$ \\
Peritoneal dialysis & $1 / 36(2.8)$ & $4 / 27(14.8)$ & \\
Transplant & $23 / 36(63.9)$ & $8 / 27(29.6)$ & \\
\hline Vital status, $\mathbf{n}(\%)$ & & & \\
Alive & $25 / 36(69.4)$ & $14 / 27(51.9)$ & $0.155 ¥$ \\
Dead & $11 / 36(30.6)$ & $13 / 27(48.1)$ & \\
\hline Complications, $\mathbf{n}(\%)$ & & & \\
Cardiovascular diseases & $14 / 36(38.9)$ & $16 / 30(53.3)$ & $0.241 ¥$ \\
Parathyroidectomy & $4 / 36(11.1)$ & $5 / 30(16.7)$ & $0.721 \AA$ \\
Gout & $3 / 36(8.3)$ & $4 / 30(13.3)$ & $0.511 \circledast$ \\
Infections & $16 / 36(44.4)$ & $17 / 30(56.7)$ & $0.323 ¥$ \\
Peripheral neuropathy & $1 / 36(2.8)$ & $1 / 30(3.3)$ & \\
Depression & $1 / 36(2.8)$ & 0 & - \\
Vertebral fracture & $1 / 36(2.8)$ & $1 / 30(3.3$ & - \\
\hline SL score corrected for BMI, mean $( \pm S D)$ & $720.3( \pm 336)$ & $625.1( \pm 193)$ & $0.289 \neq$ \\
\hline & & & \\
\hline
\end{tabular}

¥ Student’s t-test, ¥ Chi-square, ® Fishers exact test

\section{Discussion}

To our knowledge, this is the first follow up study in sub-Saharan Africa assessing the progression of vascular calcification among ESRD patients. Due to resource limitations, stringent criteria are applied to assess eligibility for state funded dialysis and subsequent transplantation. For example, patients $>60$ years and diabetics $>50$ years, morbidly obese patients and diabetics with significant target organ disease are not accepted. This explains our relatively young, non-diabetic, non-obese study population (Table 1). 
In this study we found that non-Black patients had a trend to greater progression of vascular calcification. While the sample size is small, this is consistent with numerous studies in the developed world that have shown that ethnicity is a risk factor for the progression of vascular calcification with slower progression among Blacks. ${ }^{26,27}$

Blacks in our study group had lower parathyroidectomy rates. However, studies in the USA have found higher parathyroidectomy rates among Blacks compared to non-Blacks. ${ }^{28,29}$ This contrary finding is not explained and could be confounded by the small sample size.

BMI significantly increased during the study period, likely due to the effects of transplantation as well as improved nutrition after the continuation of effective dialysis and amelioration of uremic symptoms. All females and $85 \%$ of males met African criteria for abdominal obesity. ${ }^{21}$ Obesity is regarded as a risk factor for cardiovascular disease, reduced patient survival, graft rejection and loss as well as death among patient's organ transplant recipients. ${ }^{30,31,32}$ NODAT developed in $12.1 \%$ of the patients who had received a kidney transplant and they were all Black $(p=0.131)$. This finding is consistent with published data where NODAT has been reported to occur in 2-53\% of all solid organ transplants and is a serious and common complication of kidney transplantation. ${ }^{33} 34$ In our group, weight gain was not a risk factor of developing NODAT: $1.1 \mathrm{~kg}( \pm 1.5)$ vs $4.8 \mathrm{~kg}( \pm 3.4) \mathrm{p}=0.072$. Known risk factors for developing NODAT are multifactorial and include race, age of recipient, male sex, family history of diabetes mellitus, genetics, rejection history and type of immunosuppressant therapy prescribed. ${ }^{33}$

LVH is a poor outcome predictor among patients on hemodialysis and in transplant patients. ${ }^{35,36}$ The significant regression in LVH among dialysis and transplant patients at follow up could possibly be ascribed to BP control and management of hyperparathyroidism. ${ }^{37,38}$ Left ventricular remodeling is thought to occur after renal transplant, effecting systolic and diastolic function, but the evidence is not uniform. ${ }^{39}$ After a follow up of 2 years, Rajan et al observed that kidney transplant had no association with significant regression of left ventricular mass index using cardiac magnetic resonance imaging compared to patients on the waiting list. ${ }^{40}$ However, others report that renal transplant is associated with significant LVH regression. ${ }^{41,42}$ The LVH regression among our study participants was not found to be solely due to renal transplantation.

Studies in the developed world have shown a 'survival paradox' in Blacks compared to non-Blacks. ${ }^{43,44,45}$ We did not find a difference in survival in Blacks in our cohort despite the absence of progressive vascular calcification in them. Recent studies in the USA have suggested that this apparent survival advantage is less significant in age groups above 40 years. ${ }^{14} \mathrm{~A}$ larger sample size would be needed to accurately assess this possible survival advantage in our predominantly young, Black African dialysis population. However, among participants with a known cause of death, the majority died of sepsis (64\%) which is consistent with studies done in Brazil and sub-Saharan Africa. ${ }^{46,47}$ This is likely to have obscured any difference attributable to cardiovascular causes. 
High levels of vascular stiffness are associated with CKD and dialysis dependency ${ }^{48,49}$. Higher PWV values in participants at follow up, compared to available normative age-stratified ranges, were found.

The study should be viewed in the context of its potential limitations. The sample size is small and medical data was collected from patient files thus some data could have been missing or not documented. The selection criteria for participation in the state dialysis program is rigorous due to limitation of resources and most patients are from a low-socio economic background; this could affect the replicability of these results in other cohorts ${ }^{50}$. Although it was a single center study this was a longitudinal study with a strong follow up rate of $87.8 \%$. The same investigators assessed certain clinical parameters at baseline and follow up which included abdominal X-rays and ECGs to reduce inter-observer variability.

\section{Conclusion}

In conclusion, the study describes a majority of less than 50 years old, Black, ESRD population in a resource constrained setting. Increased vascular stiffness and metabolic risk factors, were highlighted and sepsis was a major cause of death among all participants. The differences in coronary calcification progression and parathyroidectomy rates between Blacks and non-Blacks suggest ethnic variances in mineral metabolism among patients with ESRD. Further research, in a larger cohort, is needed to understand these differences and inform and improve management of all patients with CKD.

\section{Abbreviations}

BMI : Body Mass Index

CASP: Central Aortic Systolic Pressure

CCS : Coronary Calcium Scores

CKD : Chronic Kidney Disease

CV: Cardiovascular

ECG: Electrocardiogram

ESRD:End Stage Renal Disease

FGF 23 : Fibroblast Growth Factor 23

HIV: Human Immunodeficiency Virus

LVH : Left Ventricular Hypertrophy

MDRD: Modification of Diet in Renal Disease

Page 10/16 
NODAT : New Onset Diabetes after Transplantation

PWV: Pulse Wave Velocity

SA: South Africa

STATA 14: Stata Corp, College Station, Texas

\section{Declarations}

Ethics approval and consent to participate:The study protocol was approved by the Human Research Ethics Committee of the University of Cape Town (HREC REF: 048/2016).

Consent for publication : Not Applicable.

Availability of data and material: The Dataset is available on ZivaHub Open dataUCT

Competing interests : Not Applicable

Funding Not Applicable

Authors' contributions

Dr Kudakwashe SIMBA: Lead Author

Dr Megan BORKUM: Co Author

Dr Nalene STRAUSS: Data contribution

Mr Wisdom BASERA: Statistician and Data Analysis

Professor Emeritus Charles Swanepoel : Co Author

Robert Jeremy FREERCKS : Co Author

Professor Emeritus Brian Lindsay Rayner : Supervisor, Co Author

Acknowledgements

The authors gratefully acknowledge the staff and patients at Groote Schuur Hospital E13 for their support during the duration of the study.

\section{References}

1. Peer N, Steyn K, Lombard C, Lambert E V, Vythilingum B, Levitt NS. Rising diabetes prevalence among urban-dwelling black South Africans. PLoS One. 2012;7(9):e43336. 
doi:10.1371/journal.pone.0043336.

2. Study S. Lessons from the Heart of Soweto Study and future directions. SA Hear. 2011;8(2):104113.

3. Shisana, O, Rehle, T, Simbayi LC, Zuma, K, Jooste, S, Zungu N, Labadarios, D, Onoya DEA. South African National HIV Prevalence, Incidence and Behaviour Survey, 2012. HSRC Press. 2014:194.

4. Matsha TE, Yako YY, Rensburg MA, Hassan MS, Kengne AP, Erasmus RT. Chronic kidney diseases in mixed ancestry south African populations: prevalence, determinants and concordance between kidney function estimators. BMC Nephrol. 2013;14(1):75. doi:10.1186/1471-2369-14-75.

5. Isakova T, Xie H, Yang W, et al. Fibroblast growth factor 23 and risks of mortality and end-stage renal disease in patients with chronic kidney disease. JAMA. 2011;305(23):2432-2439. doi:10.1001/jama.2011.826.

6. Nitta K, Nagano N, Tsuchiya K. Fibroblast growth factor 23/klotho axis in chronic kidney disease. Nephron - Clin Pract. 2014;128(1-2):1-10. doi:10.1159/000365787.

7. Bellam N, Quyyumi A, Budoff MJ, Callister TQ, Min JK. Annals of Internal Medicine Long-Term Prognosis After Coronary Artery Calcification Testing in Asymptomatic Patients A Cohort Study. 2015;(3):14-22. doi:10.7326/M14-0612.

8. Stevens KK, McQuarrie EP, Sands W, et al. Fibroblast growth factor 23 predicts left ventricular mass and induces cell adhesion molecule formation. Int J Nephrol. 2011;2011:297070. doi:10.4061/2011/297070.

9. Pereira T, Correia C, Cardoso J. Novel methods for pulse wave velocity measurement. J Med Biol Eng. 2015;35(5):555-565. doi:10.1007/s40846-015-0086-8.

10. Temmar M, Liabeuf $S$, Renard $C$, et al. Pulse wave velocity and vascular calcification at different stages of chronic kidney disease. J Hypertens. 2010;28(1):163-169. doi:10.1097/HJH.0b013e328331b81e.

11. Blacher J, Asmar R, Djane S, London GM, Safar ME. Aortic pulse wave velocity as a marker of cardiovascular risk in hypertensive patients. Hypertension. 1999;33:1111-1117. doi:10.1161/01.HYP.33.5.1111.

12. Moe SM, Chen NX. Mechanisms of Vascular Calcification in Chronic Kidney Disease. J Am Soc Nephrol. 2008;19(2):213-216. doi:10.1681/ASN.2007080854.

13. Freedman BI, Register TC. Effect of race and genetics on vitamin D metabolism, bone and vascular health. Nat Rev Nephrol. 2012;8(8):459-466. doi:10.1038/nrneph.2012.112.

14. Kucirka LM, Grams ME, Lessler J, et al. Association of race and age with survival among patients undergoing dialysis. JAMA. 2011;306(6):620-626. doi:10.1001/jama.2011.1127.

15. Freercks R, Swanepoel C, Carrara H, Moosa S, Lachman A, Rayner B. Vascular calcification in South African dialysis patients: ethnic variation, prevalence, detection and haemodynamic correlates. Nephrology (Carlton). 2012;17(7):607-615. doi:10.1111/j.1440-1797.2012.01612.x. 
16. Redmond J, Jarjou LM a, Zhou B, Prentice a, Schoenmakers I. Ethnic differences in calcium, phosphate and bone metabolism. Proc Nutr Soc. 2014;73(March):340-351. doi:10.1017/S0029665114000068.

17. Zengin A, Prentice A, Ward KA. Ethnic differences in bone health. Front Endocrinol (Lausanne). 2015;6(MAR):1-6. doi:10.3389/fendo.2015.00024.

18. Ishii S, Cauley JA, Greendale GA, Danielson ME, Safaei Nili N, Karlamangla A. Ethnic differences in composite indices of femoral neck strength. Osteoporos Int. 2012;23(4):1381-1390. doi:10.1007/s00198-011-1723-x.

19. Ettinger B, Sidney S, Cummings SR, et al. Racial differences in bone density between young adult black and white subjects persist after adjustment for anthropometric, lifestyle, and biochemical differences. J Clin Endocrinol Metab. 1997;82(2):429-434. doi:10.1210/jc.82.2.429.

20. Freercks RJ, Swanepoel CR, Turest-Swartz KL, et al. Vascular calcification is not associated with increased ambulatory central aortic systolic pressure in prevalent dialysis patients: cardiovascular topic. Cardiovasc J Afr. 2014;25(1):4-8. doi:10.5830/CVJA-2013-081.

21. International Diabetes Federation. The IDF consensus worldwide definition of the metabolic syndrome. IDF Consens Worldw Defin Metab Syndr. 2006;28:1-7. doi:10.1159/000282084.

22. Mancia G, De Backer G, Dominiczak A, et al. 2007 Guidelines for the Management of Arterial Hypertension: The Task Force for the Management of Arterial Hypertension of the European Society of Hypertension (ESH) and of the European Society of Cardiology (ESC). J Hypertens. 2007;25(6):1105-1187. doi:10.1016/S0145-4145(08)05031-4.

23. Cuspidi C, Facchetti R, Bombelli M, et al. Does QRS Voltage Correction by Body Mass Index Improve the Accuracy of Electrocardiography in Detecting Left Ventricular Hypertrophy and Predicting Cardiovascular Events in a General Population? J Clin Hypertens. 2016;18(5):415-421. doi:10.1111/jch.12678.

24. Kauppila LI, Polak JF, Cupples LA, Hannan MT, Kiel DP, Wilson PWF. New indices to classify location, severity and progression of calcific lesions in the abdominal aorta: A 25-year follow-up study. Atherosclerosis. 1997;132(2):245-250. doi:10.1016/S0021-9150(97)00106-8.

25. Shiburi CP, Staessen JA, Maseko M, et al. Reference values for SphygmoCor measurements in South Africans of African ancestry. Am J Hypertens. 2006;19(1):40-46. doi:10.1016/j.amjhyper.2005.06.018.

26. Bild DE, Detrano R, Peterson D, et al. Ethnic differences in coronary calcification: The Multi-Ethnic Study of Atherosclerosis (MESA). Circulation. 2005;111(10):1313-1320.

doi:10.1161/01.CIR.0000157730.94423.4B.

27. Allison MA, Budoff MJ, Nasir K, et al. Ethnic-Specific Risks for Atherosclerotic Calcification of the Thoracic and Abdominal Aorta (from the Multi-Ethnic Study of Atherosclerosis). Am J Cardiol. 2009;104(6):812-817. doi:10.1016/j.amjcard.2009.05.004.

28. Kuo LE, Wachtel H, Karakousis G, Fraker D, Kelz R. Parathyroidectomy in dialysis patients. J Surg Res. 2014;190(2):554-558. doi:10.1016/j.jss.2014.05.027. 
29. Konstantinidis I, Nadkarni G, Divino CM, Lapsia V. Utilization of parathyroidectomy for secondary hyperparathyroidism in end-stage renal disease. Clin Kidney J. 2013;6(3):277-282. doi:10.1093/ckj/sft028.

30. Dimeny EM. Cardiovascular disease after renal transplantation. Kidney IntSuppl. 2002;61(00986577 (Print)):78-84. doi:10.1046/j.1523-1755.61.s80.14.x.

31. McQuarrie EP, Fellstrom BC, Holdaas H, Jardine AG. Cardiovascular disease in renal transplant recipients. J Ren Care. 2010;36 Suppl 1:136-145. doi:10.1111/j.1755-6686.2010.00160.x.

32. Svensson M, Jardine A, Fellström B, Holdaas H. Prevention of cardiovascular disease after renal transplantation. Curr Opin Organ Transplant. 2012;17(4):393-400. doi:10.1097/MOT.0b013e3283560a3b.

33. Pham P-TT, Pham P-MT, Pham S V, Pham P-AT, Pham P-CT. New onset diabetes after transplantation (NODAT): an overview. Diabetes Metab Syndr Obes. 2011;4:175-186. doi:10.2147/DMSO.S19027.

34. Palepu S, Prasad GVR. New-onset diabetes mellitus after kidney transplantation: Current status and future directions. World J Diabetes. 2015;6(3):445. doi:10.4239/wjd.v6.i3.445.

35. Paoletti E, Specchia C, Di Maio G, et al. The worsening of left ventricular hypertrophy is the strongest predictor of sudden cardiac death in haemodialysis patients: A 10 year survey. Nephrol Dial Transplant. 2004;19(7):1829-1834. doi:10.1093/ndt/gfh288.

36. Patel RK, Pennington C, Stevens KK, et al. Effect of left atrial and ventricular abnormalities on renal transplant recipient outcome-a single-center study. Transplant Res. 2014;3(1):20. doi:10.1186/s13737-014-0020-6.

37. Silberberg J, Racine N, Barre P, Sniderman AD. Regression of left ventricular hypertrophy in dialysis patients following correction of anemia with recombinant human erythropoietin. Can $\mathrm{J}$ Cardiol. 1990;6(1):1-4. http://www.ncbi.nlm.nih.gov/pubmed/2138048.

38. Di Lullo L, Gorini A, Russo D, Santoboni A, Ronco C. Left Ventricular Hypertrophy in Chronic Kidney Disease Patients: From Pathophysiology to Treatment. CardioRenal Med. 2015;5(4):254-266. doi:10.1159/000435838.

39. Souza FL de, Monteiro Junior F das C, Salgado Filho N. Effect of kidney transplantation on cardiac morphology and function. J Bras Nefrol \orgão Of Soc Bras e Latino-Americana Nefrol. 2012;34(1):94-100. doi:S0101-28002012000100016 [pii].

40. Patel RK, Mark PB, Johnston N, McGregor E, Dargie HJ, Jardine AG. Renal transplantation is not associated with regression of left ventricular hypertrophy: a magnetic resonance study. Clin J Am Soc Nephrol. 2008;3(6):1807-1811. doi:CJN.01400308 [pii]\r10.2215/CJN.01400308.

41. Ferreira SRC, Moisés V a, Tavares A, Pacheco-Silva A. Cardiovascular effects of successful renal transplantation: a 1-year sequential study of left ventricular morphology and function, and 24-hour blood pressure profile. Transplantation. 2002;74(11):1580-1587. doi:10.1097/01.TP.0000038709.70523.88.

42. McCullough PA, Chan CT, Weinhandl ED, Burkart JM, Bakris GL. Intensive Hemodialysis, Left Ventricular Hypertrophy, and Cardiovascular Disease. Am J Kidney Dis. 2016;68(5):S5-S14. 
doi:10.1053/j.ajkd.2016.05.025.

43. Badalà F, Nouri-mahdavi K, Raoof DA. NIH Public Access. Computer (Long Beach Calif). 2008;144(5):724-732. doi:10.1038/jid.2014.371.

44. Agodoa L, Eggers P. Racial and ethnic disparities in end-stage kidney failure-survival paradoxes in African-Americans. Semin Dial. 2007;20(6):577-585. doi:SDI350 [pii].

45. van den Beukel TO, Hommel K, Kamper A-L, et al. Differences in survival on chronic dialysis treatment between ethnic groups in Denmark: a population-wide, national cohort study. Nephrol Dial Transplant. 2016;31(7):1160-1167. doi:10.1093/ndt/gfv359.

46. Isla RAT, Ameh OI, Mapiye D, et al. Baseline predictors of mortality among predominantly ruraldwelling end-stage renal disease patients on chronic dialysis therapies in limpopo, South Africa. PLoS One. 2016;11(6):1-11. doi:10.1371/journal.pone.0156642.

47. Oliveira M. Survival analysis and associated factors to mortality of renal transplant recipients in a University Hospital in Maranhão. J Bras .... 2012;34(3):216-225. http://www.scielo.br/scielo.php?pid $=$ S0101-28002012000300002\&script $=$ sci_arttext\&tlng $=$ pt.

48. Fortier C, Mac-Way F, Desmeules S, et al. Aortic-brachial stiffness mismatch and mortality in dialysis population. Hypertension. 2015;65(2):378-384. doi:10.1161/HYPERTENSIONAHA.114.04587.

49. Utescu MS, Couture V, Mac-Way F, et al. Determinants of progression of aortic stiffness in hemodialysis patients: A prospective longitudinal study. Hypertension. 2013;62(1):154-160. doi:10.1161/HYPERTENSIONAHA.113.01200.

50. Kilonzo KG, Jones ESW, Okpechi IG, et al. Disparities in dialysis allocation: An audit from the new South Africa. PLoS One. 2017;12(4):e0176041. doi:10.1371/journal.pone.0176041.

\section{Figures}




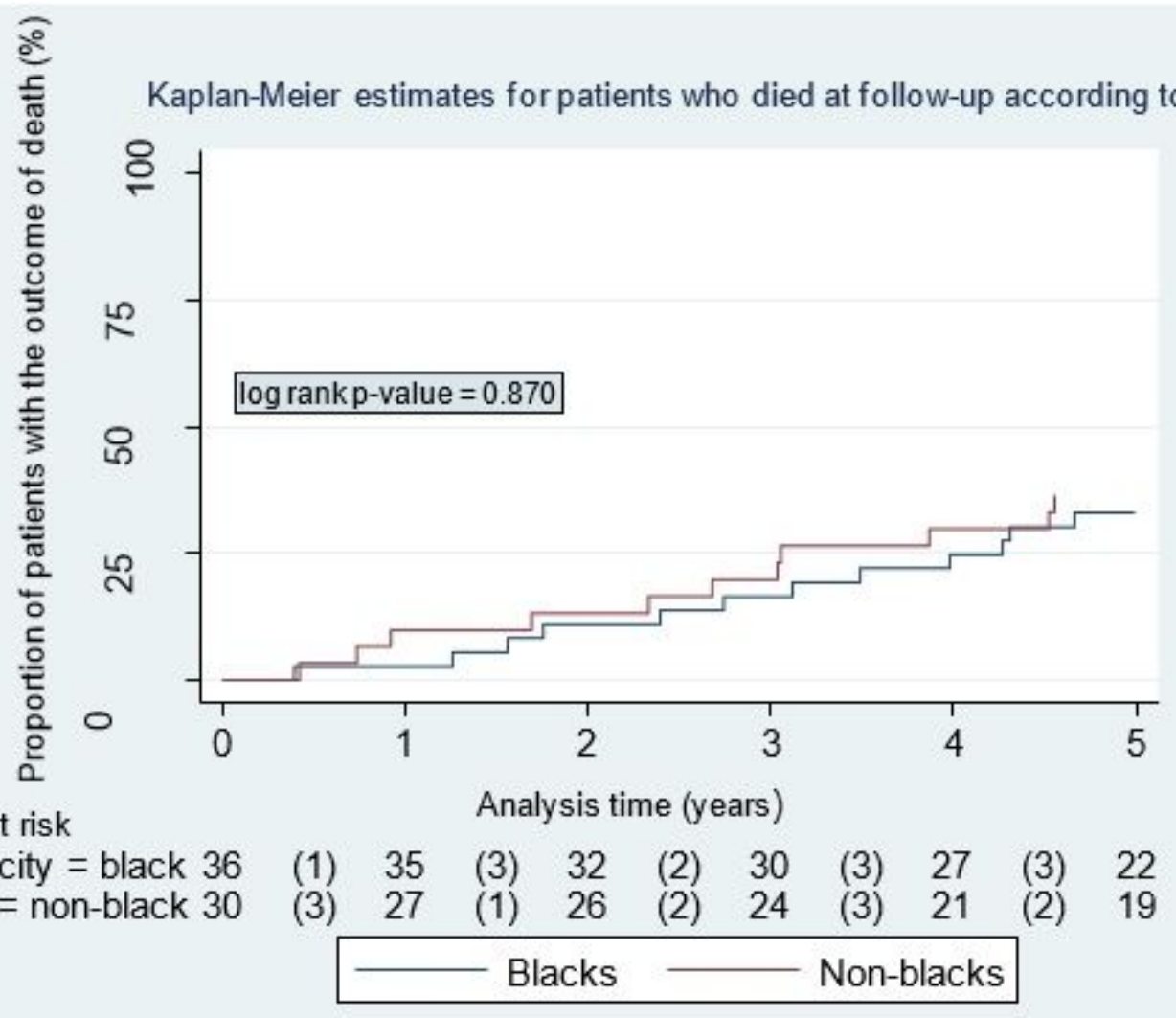

Number at risk ethnicity $=$ black 36 ethnicity $=$ non-black 30

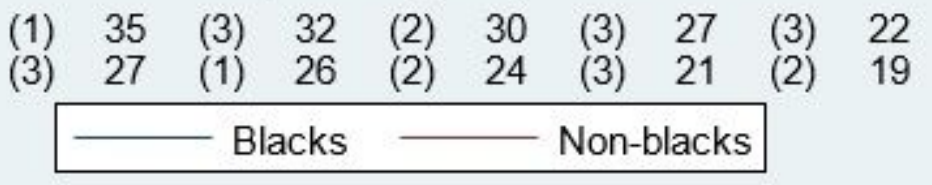

\section{Figure 1}

Kaplan - Meier estimates of patients who had died at follow-up according to race 